\title{
Is tobacco Quitline cost effective in India?
}

\author{
Raj Kumar', Shyam Kanhaiya Saroj ${ }^{2}$ \\ ${ }^{1}$ National Tobacco Quitline Services, Vallabhbhai Patel Chest Institute, University of Delhi; ${ }^{2}$ Tobacco Cessation Centre, \\ Vallabhbhai Patel Chest Institute, University of Delhi, India
}

\begin{abstract}
Quitlines are effective, evidence-based tobacco cessation interventions that help tobacco users quit through a variety of services. The present study was done to evaluate the cost effectiveness of the National Tobacco Quitline Service (NTQLS). We calculated twoyear program use and costs for establishment, salary of the staff, media promotions, intervention services, Quitline registration calls and the number of quitters since inception of NTQLS in the year 2016, we examined whether NTQLS is cost-effective or not. Out of
\end{abstract}

Correspondence: Raj Kumar, National Tobacco Quitline Services, Vallabhbhai Patel Chest Institute, University of Delhi, Delhi 110007, India.

Tel. +91.011.27667.420 - Fax: +91.011.27666549.

E-mail: rajkumarvpci@gmail.com

Keywords: Cessation; cost-effectiveness; tobacco control; quitters; quit rate; Quitline.

Author's contribution: Both the authors played a significant role in conception, design, analysis and interpretation of data, drafting article or revising it critically for important intellectual content. Both the authors have read and approved the final version of manuscript and agreed to be accountable for all aspects of the work

Ethical statement: The article does not contain the participation of any human being and/or animals.

Availability of data and materials: The datasets used and/or analyzed during the current study are available from the corresponding author on reasonable request.

Grants/Financial support: Not any grant or forms of financial support availed.

Conflict of interest: The Authors have no conflict of interest to declare.

Acknowledgements: We acknowledge the sincere efforts of the National Tobacco Quitline staffs in assisting the data collections of Quitline callers.

Received for publication: 15 May 2020.

Accepted for publication: 8 September 2020.

${ }^{\circ}$ Copyright: the Author(s), 2020

Licensee PAGEPress, Italy

Monaldi Archives for Chest Disease 2020; 90:1381

doi: 10.4081/monaldi.2020.1381

This article is distributed under the terms of the Creative Commons Attribution Noncommercial License (by-nc 4.0) which permits any noncommercial use, distribution, and reproduction in any medium, provided the original author(s) and source are credited.
63,350 callers, 9420 (97.9\% males) callers with the mean \pm SD age at $37.5 \pm 12.6$ years; were registered for tobacco cessation counselling services at the National Tobacco Quitline Services (NTQLS) between $30^{\text {th }}$ May 2016 and $31^{\text {st }}$ May 2018. 3012 (32\%) quitted their tobacco use till the last proactive calls. Average cost per completed counselling was 22.37 US\$. Our study concludes that Tobacco Quitline as a tobacco control intervention is an excellent investment and cost-effective measure in India. Average cost per quitter at 69.96 US\$ is comparatively very low to other country's Quitline, representing the ideal utilization of funds.

\section{Introduction}

Tobacco use is the world's leading cause of preventable death and disease [1]. It is critically important to allow prevention and cessation programs in every country. Tobacco Quitline is one of the special tools among the prevention and cessation program and have gained increased recognition as effective interventions for tobacco users. The key advantage of Quitline is an ability to deliver evidence-based tobacco cessation counselling to the tobacco users irrespective of their physical location or ability to pay. Most of the Quitlines offers only telephone-based counselling by reactive and proactive calls through designated toll-free number while some of the Quitlines offer pharmaceutical cessation assistance [2].

In India, the tobacco Quitline was established as a nationwide free-of-charge telephonic tobacco-based cessation service named as National Tobacco Quitline Services, before this no any other Government owned Quitline was in service to the nation. By June 2018, NTQLS was operating 72 hours per week in 2 shifts with 6 counsellors and 1 supervisor in each shift through a dedicated tollfree number 1800-11-2356. Monday of every week was assigned a weekly holiday with a 24-hour interactive voice response system back-up. The NTQLS did not use any medication as an adjunct to treatment, offering self-help cessation literature by mail or e-mail to the willing callers. NTQLS reactive services to the callers include advice or brief interventions, intensive counselling lasting approximately 20 minutes to the tobacco users in the stages of precontemplation, contemplation or have some level of intention to quit. NTQLS proactive call services include call-back to the callers who tried calling Quitline helpline number but could not connected due to busy of line or non-operational hours, and support and follow-up calls naming pre-quit date call, quit date call, post-quit date call and ongoing follow-up call to those who have registered themselves for tobacco quitting processes. The counselling aimed to deliver the knowledge about the tobacco addiction, harmful consequences of tobacco use and benefits of quitting it, increasing self-efficacy and confidence to quit, setting a quit date and preventing from lapses and relapses as per the World Health Organisation telephone-based counselling protocols. 
The tobacco Quitline is a new initiative by the government to help the tobacco user to quit. It is essential to assess the cost-effectiveness of the tobacco Quitline in Indian context. It is also important and vital for further expanding or reducing the investment or for future quality improvement processes. It is also critical to demonstrate that new intervention is cost-effective and present greater efficiencies than existing ones, viz. face-to-face counselling in clinical set-up, street play, or by any other interventions. The objective of the present study is to know whether NTQLS is a cost-effective measure.

\section{Methods}

A total of 17 experienced counsellors having degree in psychology or social work were recruited and trained to provide telephonic tobacco cessation counselling. Three supervisors having professional qualifications in counselling and supervising recruited to supervise the counsellors. A total of 4 attendants were hired to execute office clerical duties. All these 24 staffs were supervised by an Officer In-charge, a medical doctor. A core committee which has experts from various field such as law, psychology, medicine, administrations, etc. from the Ministry of Health and Family Welfare (MoHFW) and University of Delhi constituted to provide their expert guidance and consultation for efficient functioning of Quitline. Operational guidelines, rules and regulations, funding to tobacco Quitline managed by Ministry of Health and Family Welfare, Government of India. For all other technical requirements, professionals were outsourced. The Quitline was operational 72 hours in a week in two shifts each day (i.e., 8 a.m. to 2 p.m. and 2 p.m. to 8 p.m.) with 6 workstations seated by 6 counsellors at a time in a shift, backed by $2-3$ counsellors.

Two-year data, about calls at interacted voice response system (IVR), reactive and proactive calls, and registered tobacco users at NTQLS were analysed. A tobacco user willing to quit tobacco use registered him or her by calling at NTQLS toll-free number. After registration the quit date was set within a week. Minimum of four follow-up (proactive) calls were made to provide tobacco cessation counselling. Those abstained from tobacco use from the date of quit date to last three proactive calls were labelled as quitters, usually 3 4 weeks. To calculate the cost on per registered caller and per quitter cost, during a two-year program from $30^{\text {th }}$ May 2016 to $31^{\text {st }}$ May 2018 and costs for establishment, salary of the staff, media promotions and intervention services were computed in addition to Quitline registration calls and the number of quitters excluding the electricity charges, which is maintained and paid by the Vallabhbhai Patel Chest Institute.

The cost per completed counselling at NTQLS over the 2-year period (2016-2018) is calculated as the total cost of the NTQLS over this period divided by total number of tobacco users who completed counselling over the same period. Meanwhile cost per quitter is calculated as the total cost of the NTQLS over this period divided by the number of individuals who have quitted their tobacco use till last follow-up, usually 3-4 weeks.

\section{Formulae*}

Cost per completed counselling $=$

Total costs to provide the intervention

Number of callers registered for a defined time period

Cost per Quitter $=$

Total costs to provide the intervention

Number of callers who quit tobacco use for a defined period of time

*North American Quitline Consortium 2010

To compare cost effectiveness of NTQLS with other countries Quitlines, all costs incurred at NTQLS (in Indian Rupees (₹)) converted to US dollars (US\$). Exchange rate on 08-11-2018 (1 US\$ $=72.91$ ₹) was taken as base for the conversion. The average cost per quitter was adjusted to current year inflation based on Consumer Price Index (CPI) - 2018 [19-22].

\section{Statistical analysis}

Data analysis, averages and calculation were done through MS-Excel 2010.

\section{Results}

There were 63,350 callers $(0.024 \%$ of the total tobacco users in India aged above 15 years) at the NTQLS during the study period of two years a total of 78,924 inbound calls and a total of 164,560 outbound calls were made during this period. A total of 9420 callers ( $97.9 \%$ male, $2.1 \%$ female), the mean \pm SD age was $37.5 \pm 12.6$ years were registered for tobacco cessation counselling, rest seek information for their known tobacco users, such as friend, spouse, relatives and callers who were in pre-contemplated stage but could not be turned into contemplation stage. An average of 15-20 min free telephone-based counselling by the Quitline counsellor helped 3012 $(32 \%)$ tobacco users to successfully quit their tobacco use on the set quit date and abstained till post quit date calls as well as on other ongoing follow-up calls, usually 3-4 weeks. Average cost per completed counselling was found to be ₹1631 (22.37 US\$) and average cost per quitter was ₹5101 (69.96 US\$), including the fixed cost while it was ₹1467 (20.12 US\$) and ₹4587 (62.91 US\$), respectively excluding the fixed cost (Tables 1 and 2). Yearly cost per completed

Table 1. Cost per completed counselling and per quitter including fixed cost from $30^{\text {th }}$ May 2016 to $31^{\text {st }}$ May 2018 at National Tobacco Quitline Services

\begin{tabular}{lc} 
Particulars & Cost in INR (US \$) \\
Cost on fixed asset and equipment & $1,550,000$ \\
Telephone bills, educational materials, advertisements, other overhead expenses & $1,379,708$ \\
\hline Salary of staff & $12,436,135$ \\
Total cost & $15,365,843$ \\
\hline Cost per completed counselling $[$ i.e., total cost divided by total no. of registered callers $(\mathrm{n}=9420)]$ & $15,365,843 / 9420=1631(22.37)$ \\
Cost per quitter i.e., total cost divided by total no. of quitters $(\mathrm{n}=3012)]$ & $15,365,843 / 3012=5101(69.96)$
\end{tabular}


counselling and cost per quitter excluding fixed cost are presented in Table 2. Results of the present study showed that cost per quitter at NTQLS is lowest among the all other Quitlines operating in other countries (Table 3).

\section{Discussion}

Tobacco related diseases and economic loss is one of the crucial problems in India. After getting the scientific evidence of tobacco being a major cause of mortality and morbidity, Government of India started growing awareness programs about the adverse health effects of tobacco use and in 1975, the first national level antitobacco legislation called the Cigarettes (Regulation of Production, Supply and Distribution) Act, 1975, which mandated health warnings on cigarette packets and cigarette advertisements enacted [3]. Since Cigarette Act, 1975, dealt with only cigarette and do not dealt with other tobacco product such as bidi and smokeless tobacco, this Act was replaced in the year 2003 by the new Act, namely, "The Cigarettes and other Tobacco Products (Prohibition of Advertisement and Regulation of Trade and Commerce, Production, Supply and Distribution) Act, 2003" [4]. India also ratified the WHO-Framework Convention on Tobacco Control (WHO-FCTC) in February 2004 and became a Party to the WHO Framework Convention on Tobacco Control on February 27, 2005 [5]. Further, in order to create greater awareness about the harmful effects of tobacco and effective implementation of the Tobacco Control Law and also to fulfil the obligations under the WHOFCTC, the Ministry of Health and Family Welfare, Government of India launched the National Tobacco Control Program (NTCP) in 2007- 08 in 42 districts of 21 States/Union Territories of the country [4,5]. In the year 2016, telephone-based Tobacco Quitline launched which started its tobacco cessation counselling services all over India but has raised many doubts and questions about its effectiveness and people participations. In more than 53 countries, telephone based Quitlines had already been operating since last two decades and proved successful but in India according to Indian culture, social stigma and diversity it was thought that it might not be as successful as in other developed countries.

Unless the evidence is present, it is not acceptable to simply state that an intervention is effective, therefore, to evaluate effectiveness in terms of delivery of intervention as well as its costeffectiveness present study was done at NTQLS, VPCI. Results of this study showed that NTQLS has been accessed by 63,350 tobac- co users in two years which represents $0.024 \%$ of the current tobacco users of India. Studies showed that a Quitline has the potential to reach at least $4 \%$ to $6 \%$ of total tobacco users in a year in a country [6]. The figure at NTQLS is very small but that is too remarkable due to the fact that it had not taken help of any commercial advertising. The news spread in media and publicity by word of mouth in National conferences, local camps and meetings were the sole and prime medium of creating the 63,350 callers at NTQLS. A study of Thailand National Quitline reported 116,862 callers in three years (between 2009 and 2012) that is almost quite equal to the NTQLS. ${ }^{7}$

Studies across the world gave much evidence to show the effectiveness of tobacco Quitline [6-12]. In the present study the effectiveness can be seen in term of delivery of intervention as well as cost effectiveness. An average of 15-minute counselling helped 3012 (32\%) callers to quit their tobacco use habit incurring a cost of ₹1631 (22.37 US\$) per completed counselling. An average per quitter cost during two-year period found to be ₹5101 (69.96 US\$) that is quite low in comparison to other countries Quitlines cost. In 2003, Oregon Quitline, USA intensive counselling achieved a quit rate of $14.3 \%$ at a cost of $\$ 132$, moderate counselling achieved a quit rate of $13.8 \%$ at a cost of $\$ 107$, and brief counselling achieved a quit rate of $11.7 \%$ at a cost of $\$ 67$ [13]. The Thailand Quitline recorded $38 \%$ continuous abstinence rates at 3-month with an average cost of $\$ 31$ per completed counselling and $\$ 253$ per quitter [7]. The cost per quitter at Swedish Quitline in the year 2001 was 10521360 US\$ [14].

National Tobacco Quitline Services do not offer any medication but there were some Quitlines in other countries who offered Nicotine Replacement Therapy (NRT) adjunct to telephone based counselling and have a higher quit rate in comparison to telephonebased counselling without medication. Results of Oregon Quitline 2003 study where intensive counselling offered with NRT achieved a highest quit rate of $21.2 \%$ at a cost of $\$ 268$ per participant [13]. In another study done by Minnesota Quitline, the 30-day abstinence at six months increased after allowing NRT (from $10.0 \%$ pre-NRT to $18.2 \%$ post-NRT) with a cost of $\$ 1362$ per quit on pre-NRT and \$1934 post-NRT [5].

National Tobacco Quitline Services at VP Chest Institute is effective in terms of accessibility as during a two-year period, 63,350 callers accessed the tobacco Quitline toll-free number including elderly, rural residents, minorities and the poor for at least a brief advice or information on tobacco cessation. In these two years (2016-2018) total cost of NTQLS including fixed and operating cost incurred was Rupees $15,365,843$ (210,750 US\$).

Table 2. Cost per completed counselling and per quitter excluding fixed cost during the study period at National Tobacco Quitline Services.

\begin{tabular}{|c|c|c|c|}
\hline Particulars & $\begin{array}{c}30^{\text {th }} \text { May } 2016- \\
31^{\text {st }} \text { May } 2017 \\
\text { Cost in INR (US } \$ \text { ) }\end{array}$ & $\begin{array}{c}1^{\text {st }} \text { June } 2017- \\
31^{\text {st }} \text { May } 2018 \\
\text { Cost in INR (US \$) }\end{array}$ & $\begin{array}{c}30^{\text {th }} \text { May } 2016- \\
31^{\text {st }} \text { May } 2018 \\
\text { Cost in INR (US } \$ \text { ) }\end{array}$ \\
\hline $\begin{array}{l}\text { Telephone bills, educational materials, advertisements, } \\
\text { other overhead expenses }\end{array}$ & 963,634 & 416,073 & $1,379,707$ \\
\hline Salary of staff & $6,769,385$ & $5,666,750$ & $12,436,135$ \\
\hline Total cost & $7,733,019$ & $6,082,823$ & $13,815,842$ \\
\hline $\begin{array}{l}\text { Cost per completed counselling } \\
\text { [i.e., total cost divided by total no. of registered callers (n)] }\end{array}$ & $\begin{array}{c}7,733,019 / 5179=1493(20.48) \\
{[n=5179]}\end{array}$ & $\begin{array}{c}6,082,823 / 4241=1434(19.67) \\
{[n=4241]}\end{array}$ & $\begin{array}{c}13,815,842 / 9420=1467(20.12) \\
{[n=9420]}\end{array}$ \\
\hline $\begin{array}{l}\text { Cost per quitter } \\
\text { [i.e., total cost divided by total no. of quitters (n)] }\end{array}$ & $\begin{array}{c}7,733,019 / 2010=3847(52.76) \\
(\mathrm{n}=2010)\end{array}$ & $\begin{array}{l}6,082,823 / 1002=6071(83.26) \\
(\mathrm{n}=1002)\end{array}$ & $\begin{array}{c}13,815,842 / 3012=4587(62.91) \\
(\mathrm{n}=3012)\end{array}$ \\
\hline
\end{tabular}


Comparing with face to face counselling, a total of 74,471 tobacco users were counselled in 21 states of India during the period 20122015 , incurring an expenditure of about Rupees 97.58 crores (13.38 million US\$) [16] under National Tobacco Control Program use (NTCP), but how many had quit was unrecognisable. Our previous study demonstrated the effectiveness of NTQLS, with a quit rate of $38.8 \%$ [17]

\section{Conclusions}

Results of the present study showed that Tobacco Quitline (NTQLS) at V.P. Chest Institute, Delhi is a cost-effective program, under the initiative of Ministry of Health and Family Welfare, Government of India, in our country with a low average cost per quitter compared to other Tobacco Quitlines operating in different countries. It is also found to be an effective measure of tobacco control in India in terms of accessibility, and numbers of quitters. However, the limitation of the present study was the follow-up, which was of only a four-week. The percentage of tobacco quitters could vary in longer time period follow-ups. Expansion of National Tobacco Quitline Services is required to reach the current 267 million tobacco users in the country with other regional language options as presently this service is available only in Hindi and English. Addition of nicotine replacement therapy to telephone-based counselling to the callers may increase the quit rates.

\section{What this paper adds}

1. This is the first detailed analysis of the cost incurred in establishing and operating first tobacco Quitline in India for two years.

2. This study reveals that telephone-based tobacco cessation services (Quitline) are cost-effective cessation tools for a country.

3. This forms a significant contribution for tobacco control policy maker to start and own tobacco Quitline adjunct to other tobacco control program.

Table 3. Comparison of cost per quitter at NTQLS with other countries' Quitline.

\begin{tabular}{|c|c|c|c|c|c|c|c|}
\hline $\begin{array}{l}\text { Country } \\
\text { (year established) }\end{array}$ & Name of Quitline & $\begin{array}{l}\text { Intervention } \\
\text { offered }\end{array}$ & $\begin{array}{l}\text { Year } \\
\text { of study }\end{array}$ & Duration of quitting & $\begin{array}{l}\text { Quit } \\
\text { rates } \\
(\%)\end{array}$ & $\begin{array}{c}\text { Avg. Cost } \\
\text { per quitters }\end{array}$ & $\begin{array}{l}\text { Avg. cost } \\
\text { s per quitter } \\
\text { adjusted to } \\
\text { CYI - } 2018\end{array}$ \\
\hline Denmark [18](1999) & STOP-liniens Rådgivning & Reactive only & 2006 & 12 months point prevalence & 23.5 & $€ 165$ & $€ 195=\$ 220$ \\
\hline Germany [18](1999) & Raucher-Telefone & $\begin{array}{l}\text { Reactive } \\
\text { Proactive }\end{array}$ & 2006 & 12 months point prevalence & 26.5 & $€ 126$ & $€ 149=\$ 168$ \\
\hline Iran [18](1999) & National Smokers' Quitline & $\begin{array}{l}\text { Reactive } \\
\text { Proactive }\end{array}$ & 2006 & 12 months point prevalence & 31.6 & $€ 88$ & $€ 104=\$ 118$ \\
\hline Italy [18](1999) & S.O.S. FUMO & $\begin{array}{l}\text { Reactive } \\
\text { Proactive }\end{array}$ & 2006 & 12 months point prevalence & 14 & $€ 61$ & $€ 72=\$ 81$ \\
\hline Minnesota (USA) [18] (2001) & ) Minnesota Quitline & $\begin{array}{l}\text { Reactive } \\
\text { Proactive }\end{array}$ & 2006 & 12 months point prevalence & 10 & $\$ 1362$ & $\$ 1362=\$ 1710$ \\
\hline Minnesota (USA) [18] (2001) & Minnesota Quitline & $\begin{array}{l}\text { Reactive } \\
\text { Proactive } \\
\text { NRT }\end{array}$ & 2006 & 12 months point prevalence & 18.2 & $\$ 1934$ & $\$ 1934=\$ 2428$ \\
\hline Netherlands [18](2000) & STIVORO & $\begin{array}{l}\text { Reactive } \\
\text { Proactive }\end{array}$ & 2006 & 12 months point prevalence & 22.4 & $€ 217$ & $€ 257=\$ 290$ \\
\hline Norway [18](1996) & Røyketelefonen & $\begin{array}{l}\text { Reactive } \\
\text { Proactive }\end{array}$ & 2006 & 12 months point prevalence & 28.9 & $€ 88$ & $€ 104=\$ 117$ \\
\hline Oregon (USA) [13](1998) & Oregon Tobacco Quit Line & $\begin{array}{l}\text { Reactive } \\
\text { Proactive }\end{array}$ & 2003 & 1 month continuous abstinence & 14.3 & $\$ 132$ & $\$ 132=\$ 180$ \\
\hline Oregon (USA) [13](1998) & Oregon Tobacco Quit Line & $\begin{array}{l}\text { Reactive } \\
\text { Proactive } \\
\text { NRT }\end{array}$ & 2003 & 1 month continuous abstinence & 21.2 & $\$ 268$ & $\$ 268=\$ 365$ \\
\hline Portugal [18] (2002) & SOS Deixar de Fumar & $\begin{array}{l}\text { Reactive } \\
\text { Proactive }\end{array}$ & 2006 & 12 months point prevalence & 32 & $€ 107$ & $€ 127=\$ 143$ \\
\hline Sweden [14](1998) & Swedish Quitline & $\begin{array}{c}\text { Reactive } \\
\text { Proactive } \\
\text { NRT } \\
\text { Non-NRT (Bupropion) }\end{array}$ & 2001 & 12 months point prevalence & 31 & $\$ 1052$ & $\$ 1052=\$ 1498$ \\
\hline Thailand [7](2008) & $\begin{array}{l}\text { Thailand National Quitline } \\
\text { (TNQ) }\end{array}$ & $\begin{array}{l}\text { Reactive } \\
\text { Proactive }\end{array}$ & 20136 & 6 months continuous abstinence & 38 & $\$ 253$ & $\$ 253=\$ 270$ \\
\hline India (2016) & $\begin{array}{l}\text { National Tobacco Quitline } \\
\text { Services (NTQLS) }\end{array}$ & $\begin{array}{l}\text { Reactive } \\
\text { Proactive }\end{array}$ & 2018 & 1 month continuous abstinence & 32 & $\$ 69.96$ & $\$ 69.96=\$ 69.96$ \\
\hline
\end{tabular}

CYI, current year inflation compared with United Sates inflation consumer price index, References. [19-22]. 


\section{References}

1. WHO. Tobacco Factsheets. Accessed: 12th October 2018. Available from: http://www.who.int/news-room/fact-sheets/ detail/tobacco

2. Centers for Disease Control and Prevention. Telephone Quitlines: A resource for development, implementation, and evaluation. Final edition. Atlanta, GA: U.S. Department of Health and Human Services, Centers for Disease Control and Prevention, National Center for Chronic Disease Prevention and Health Promotion, Office on Smoking and Health; 2004.

3. Indian Railway. The cigarettes (regulations of production, supply and distribution) ACT, 1975. Accessed: 12th October 2018. Available from: http://www.indianrailways.gov.in/railwayboard/uploads/directorate/security/rpf/Files/law/BareActs/cigaretts_act1975.html

4. Jiloha RC. National Tobacco Control Program. Delhi Psychiat J 2010;13:211-28.

5. Ministry of Health and Family Welfare. National Tobacco Control Program. Accessed: 12th October 2018. Available from: https://mohfw.gov.in/sites/default/files/About\%20NTCC.pdf

6. World Health Organization. Benefits and rationale for establishing quit-line services. Accessed: 12th October 2018. Available from: http://who.int/tobacco/publications/smoking_cessation/ benefits_and_rationale_est_who_tobacco_quit_line_services. pdf?ua $=1$

7. Meeyai A, Yunibhand J, Punkrajang P, Pitayarangsarit S. An evaluation of usage patterns, effectiveness and cost of the national smoking cessation quitline in Thailand. Tob Control 2015;24:481-8.

8. Stead LF, Hartmann-Boyce J, Perera R, Lancaster T. Telephone counselling for smoking cessation. Cochrane Database Syst Rev 2013;CD002850. Update in: Cochrane Database Syst Rev 2019;5:CD002850. doi: 10.1002/14651858.CD002850.pub4.

9. Carreras JC, Fletes ID, Quesada ML, et al. [Design and early results of a proactive telephone-based smoking cessation treatment compared with face-to-face group sessions].[Article in Spanish]. Med Clin (Barc) 2007;128:247-50.

10. Fiore MC, Jaén CR, Baker TB, et al. Treating tobacco use and dependence: 2008 update. Rockville, MD: US Department of Health and Human Services; 2008.
11. Lichtenstein E, Zhu SH, Tedeschi GJ. Smoking cessation quitlines: an underrecognized intervention success story. Am Psychol 2010;65:252-61.

12. Simpson SA, Nonnemaker JM. New York tobacco control program cessation assistance: costs, benefits, and effectiveness. Int J Environ Res Public Health 2013;10:1037-47.

13. Hollis JF, McAfee TA, Fellows JL, et al. The effectiveness and cost effectiveness of telephone counselling and the nicotine patch in a State Tobacco Quitline. Tob Control 2007;16:153-9.

14. Tomson T, Helgason AR, Gilljam H. Quitline in smoking cessation: a cost-effectiveness analysis. Int J Technol Assess Health Care 2004;20:469-74.

15. An LC, Schillo BA, Kavanaugh AM, et al. Increased reach and effectiveness of a statewide tobacco quitline after the addition of access to free nicotine replacement therapy. Tob Control 2006;15:286-93.

16. Press Information Bureau, Government of India. National Tobacco Control Program. Accessed 16th October 2018. Available from: https://nhm.gov.in/index1.php?lang=1\&level $=2 \&$ sublinkid $=1052 \&$ lid $=607$

17. Kumar R, Jha AK, Munish VG, et al. National tobacco Quitline: The preliminary Indian experience. Indian J Chest Dis Allied Sci 2018;60:7-12.

18. Willemsen MC, Van der Meer RM, Bot S. Description, effectiveness, and client satisfaction of 9 European Quitlines: Results from the European Smoking Cessation Helplines Evaluation Project (ESCHER). Den Haag: STIVORO; 2008.

19. Bureau of Statistics. Calculate Euro purchasing power change due to inflation for custom period. Accessed 29th December 2018. Available from: https://www.statbureau.org/en/eurozone/inflation-calculators

20. U.S. Department of Labor, Bureau for Labor Statistics. Consumer Price Index. Accessed 29th December 2018. Available from: https://www.bls.gov/cpi/

21. Open Government Data Platform India. All India Consumer Price Index (Rural/Urban). Accessed 29th December 2018. Available from: https://data.gov.in/catalog/all-india-consumer-price-index-ruralurban

22. Maple Tech International LLC. Inflation Calculator with U.S. CPI Data. Accessed 29th December 2018. Available from: https://www.calculator.net/inflation-calculator.html 